\title{
A Group Decision-Making Method for Selecting Cloud Computing Service Model
}

\author{
Ibrahim M. Al-Jabri \\ Department of Accounting and \\ Management Information Systems \\ College of Industrial Management \\ King Fahd University of Petroleum \\ and Minerals \\ Dhahran, Saudi Arabia
}

\author{
Mustafa I. Eid \\ Dammam Community College \\ King Fahd University of Petroleum \\ and Minerals \\ Dhahran, Saudi Arabia
}

\author{
M. Sadiq Sohail \\ Department of Management and \\ Marketing \\ College of Industrial Management \\ King Fahd University of Petroleum \\ and Minerals \\ Dhahran, Saudi Arabia
}

\begin{abstract}
Cloud computing is a new technology that has great potential for the business world. Many business firms have implemented, are implementing, or planning to implement cloud computing technology. The cloud computing resources are delivered in various forms of service models which make it challenging for business customers to select the model that suits their business needs. This paper proposes a novel group-based decision-making method where a group of decision makers is involved in the decision process. Each decision maker provides weights for the cloud selection criteria. Based on weight aggregations and deviations, decision makers would select the alternative which has the highest ratio of deviation to mean is selected. The method is illustrated with an example on the selection of cloud service models. This method is useful for IT managers in selecting the appropriate cloud service model for their organizations.
\end{abstract}

Keywords-Cloud computing; cloud service models; multicriteria decision-making; group decision-making

\section{INTRODUCTION}

According to Forrester [1], the projected public cloud market will generate a revenue of US\$191 billion by 2020 . This includes US\$133 billion for cloud applications, US $\$ 44$ billion for cloud platforms, and US\$14 billion for cloud business services. Etro [2] reported that cloud computing tends to increase in new business formation in European economies as it reduces cost of entry into a market by saving in capital expenditure on IT. The European Business Research Center estimates cloud computing would generate, between 2010 and 2015, a cumulative increase in output of $€ 763$ billion in five European countries (France, Germany, Italy, Spain and the UK), and an increase in employment of 2.3 million [3]. During these five years, the CEBR predicted that the annual economic benefits would be more than $€ 177$ billion and an annual increase of 446,000 jobs.

In an era of information and globalization, an immense computing power is required to empower business intelligence and competitive gains. Nonetheless, operating a private data centre and managing software licensing to meet a growing computing processing demands is complex and costly. Cloud computing represents a shift in computing paradigm which comprises outsourcing of computing resources with characteristics like on-demand self-service, resources scalability, zero up-front investment, and measured services; it also promises to provide a solution in the form of on-demand computing, swift deployment, little required maintenance, fewer IT staff and low cost [4]. Such captivating promises has made this technology a primary academic research and business media topic over the last few years. However, serious security and privacy concerns have made businesses reluctant to deploy cloud computing [5]-[13].

Due to the immense benefits, opportunities and serious concerns in adopting cloud computing [14]-[16], it is important to select the right cloud service model that satisfies the business requirements. Businesses face a number of challenging decisions with respect to the selection of the appropriate cloud service models, like SaaS, PaaS, or IaaS. The decision involves considering organizational and technological factors, business information needs, and budget requirements. The decision is a challenging and complex because it requires due consideration of several conflicting factors that need to be dealt with simultaneously. This study proposes a novel method that is based on MCDM and incorporates a group of decision makers in the selection of cloud service model. The method aggregates the weights of the selection criteria for each decision maker and rank the cloud service models based on the ratio of deviation among to aggregate mean of the decision makers.

The rest of the paper is organised as follows. Section 2 provides an overview of cloud computing and the selection factors of cloud computing models. Section 3 presents different multi-criteria decision-making methods in cloud computing. Section 4 explains in details the proposed method in selecting cloud computing service model. Section 5 demonstrates the proposed method with a numerical example. Section 6 concludes the papers and offers future research direction.

\section{OVERVIEW OF CLOUD COMPUTING}

The idea of delivering software application and computing processing power from a computer network herein labelled "cloud computing" is not entirely new. Cloud computing has its roots within grid computing, service-oriented architecture, distributing computing, and virtualization [17]-[20]. John McCarthy, in his speech at the MIT Centennial in 1961, predicted that computing would become a public utility [21]. Carr [22] predicted that IT resources are going to be supplied as services in a manner similar to the supply of electricity by 
power companies. Power companies based on demand and charged based on use, and no need for households or factories to run dedicated power generators to supply electricity. He also argued that since IT services would be available to everyone, companies would not anymore consider IT as a competitive weapon. Carr's viewpoint of IT being supplied based on demand and charged based on use like electricity is very much supported by the emergence of cloud computing technology.

Cloud computing has become the topic of almost every IT forum today. Over the years, IT has made remarkable advancements. Most notable advances are in the areas of virtualization, hardware and software infrastructure and web technologies. Cloud computing enables user to gain access to information and to lower the barriers to computing. With cloud computing, the need to maintain technology infrastructure fades out as the burden of system management and data protection is shifted to cloud service providers [19]. The adoption of cloud computing is changing IT service delivery models, enabling changes in IT agility, re-engineering business processes, revolutionizing the use of applications, and interacting with consumers and other companies.

\section{A. Defining Cloud Computing}

Both academics and industry have proposed various definitions for cloud computing but no one definition has gained mutual consensus so far. Buyya et al. [18] defined cloud computing as "a type of parallel and distributed system consisting of a collection of inter-connected and virtualized computers that are dynamically provisioned and presented as one or more unified computing resource(s) based on servicelevel agreements established through negotiation between the service provider and consumers." According to Armbrust et al. [23], "Cloud computing refers to both the applications delivered as services over the Internet and the hardware and systems software in the data centers that provide those service." Kramer [24] defined it as "a new computing paradigm, which changes the purchasing, maintenance and disposal process of IT by providing on-demand procurement of a dynamic basket of IT resources, these resources are hosted in specialized data centers and can be purchased and scaled over the Internet, on-demand and location independently." The most acknowledged definition of cloud computing in literature is the one presented by the National Institute of Standards and Technology (NIST). NIST defines cloud computing as "A model for enabling convenient, on-demand network access to a shared pool of configurable computing resources (e.g. networks, servers, storage, applications, and services) that can be rapidly provisioned and released with minimal management effort or service provider interaction", [25, p. 11]. Furthermore, NIST described the cloud computing as consisting of five essential characteristics, three service delivery models, and four deployment models. The essential characteristics are broad network access, measured service, rapid elasticity and on-demand self-service. The service models are Software as a Service (SaaS), Platform as a Service (PaaS), and Infrastructure as a Service (IaaS); and the deployment models are private cloud, public cloud, hybrid cloud, and community cloud. The five essential characteristics, three cloud service models, and four cloud deployment models are depicted in Fig. 1.

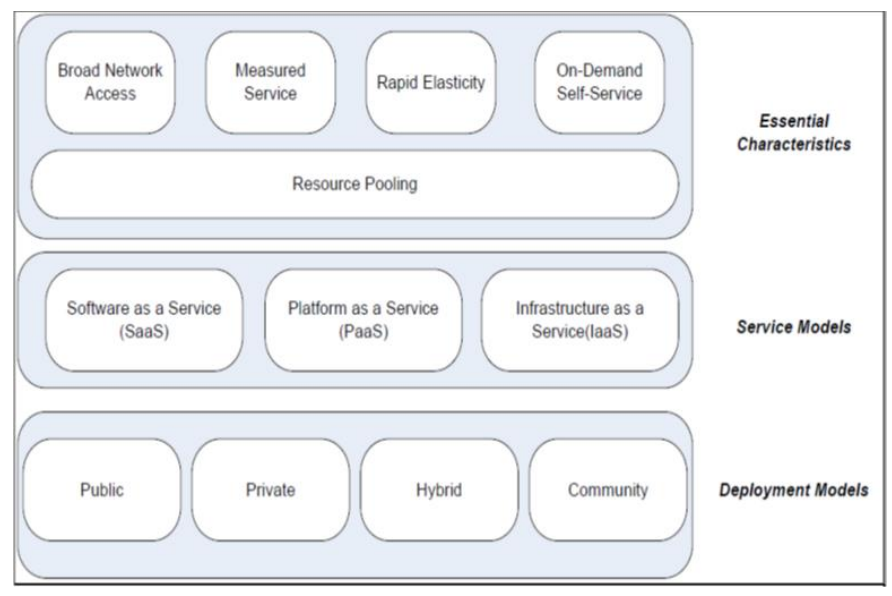

Fig. 1. NIST visual model of cloud computing definition [26].

\section{B. The Service Delivery Models}

- Software as a Service (SaaS) provides applications and software to the consumer. The applications are accessible from various client devices through either a thin client interface, such as a web browser, or a program interface. The consumer does not manage or control the underlying cloud infrastructure including network, servers, operating systems or storage devices.

- Platform as a Service (PaaS) is the deployment of operating systems, programming languages, libraries, services, and tools supported by the provider. The consumer does not manage or control the underlying cloud infrastructure including network, servers, or operating systems, but has control over the deployed applications and possibly configuration settings for the application-hosting environment.

- Infrastructure as a Service (IaaS) is the provision of basic hardware and software needed for processing power, storage space, communication networks, and other necessary computing resources where the consumer is able to deploy and run the needed system and application software.

\section{The Selection Factors of Cloud Computing Service Models}

Eid et al. [27] conducted an extensive review of literature where they identified the factors that affect the adoption of cloud computing in organizations. We will select the most important factors we believe very relevant to the selection of a service delivery model. The following seven factors along with their brief descriptions represent organizational and technical conditions relevant to the selection of service delivery models:

- Cost: the cost of leasing service delivery model (SaaS, PaaS, or IaaS). It includes total amount charged by the cloud provider as well as maintenance and support cost [28].

- Adaptability: the level of service delivery model flexibility with respect to changing user requirements, and needs of the organization adopting cloud computing [29]. 
- Available IT skills: degree of IT skills availability in the organization adopting cloud computing [30].

- Urgency: degree of urgency of needed cloud service which allows for faster deployment and immediate cloud service provisioning [31].

- Security of data: security level of the used service and client data maintained by the cloud deployment model. This includes: 1) data integrity (data accuracy and recovery), 2) level of audibility and 3) access control [28], [32], [33].

- Privacy of data: degree of confidentiality of data maintained by the cloud provider [32].

- Service reliability: the extent to which the service is available without interruption or with minimum downtime.

\section{Multi-Criteria DeCiSiOn-MAKING IN ClOUd COMPUTING}

Multi-criteria decision-making (MCDM) is a branch of operations research/management science that is concerned with the methods and techniques to solve the multi-criteria decision problems. Gavade [34] classified multi-criteria decisionmaking problems into two categories:

- Multiple attribute decision-making (MADM): MADM involves the selection of the "best" alternative from prespecified alternatives described in terms of multiple attributes; and

- Multiple objective decision-making (MODM): MODM involves the design of alternatives which optimize the multiple objectives of Decision Maker (DM).

Multi-Criteria Decision-Making (MCDM) provides effective approach in many economical, manufacturing, material, service selection problems [35]. It specifically plays an important role in areas of investment decision, product evaluation, staff appraisal and others [34]. Despite a long history, researchers constantly develop methods based on the MCDM approach. These methods differ in both implementation details and scope of application. Each method has its own strengths and weaknesses. There are several methods of multi-criteria decision-making. In their research, Whaiduzzaman et al. [35] provided a taxonomy of MCDM- based methods along with their objectives, criteria/approach, strengths, and limitations. Examples of the reviewed MCDM methods are:

- Analytic Hierarchy Process (AHP).

- Analytic Network Process (ANP).

- Technique for Order of Preferences by Similarity to Ideal Solution (TOPSIS).

- Elimination and Et Choice Translating Reality (ELECTRE).

- Preference Ranking Organization METHod of Enrichment Evaluations (PROMETHEE).

- Decision-Making Trial and Evaluation Laboratory (DEMATEL).

- Grey Relational Analysis (GRA).

- Simple Additive Weighting (SAW).

- Fuzzy MCDM.

- Data Envelopment Analysis (DEA).

As cloud computing technology adoption has become more popular during the last few decades, researchers have paid more attention to address the managerial decision-making issues faced by organizations interested to adopt cloud computing. Conway and Curry [35] addressed the management of cloud computing adoption from a lifecycle approach perspective. They developed a lifecycle model for managing cloud-computing adoption. Whaiduzzaman et al. [36] focused on addressing the service selection for cloud computing using the multi-criteria decision-making approach. They described the multi-criteria decision analysis (MCDA) types and characteristics and compared several methods by synthesizing and reviewing the present literature. The selection of cloud service models by organizations necessitates the consideration of a number of related conflicting factors that are relevant to the cloud service models and organizational requirements. In such multiple criteria decision situations, a compromise or tradeoff has to be made because in most real-world situations, no single alternative satisfies all criteria but one alternative may be better in terms of some of the criteria while other alternatives may outperform it, if judged based on the remaining criteria [37].

TABLE I. SELECTION PROBLEMS IN CLOUd COMPUTING

\begin{tabular}{|l|l|l|l|}
\hline SN & Selection Problems & MCDM Method & Reference \\
\hline 1 & Cloud service selection & BSC, FDM, FAHP & {$[38]$} \\
\hline 2 & Cloud computing vendor selection & TOPSIS, SAW, AHP & ANP \\
\hline 3 & Adoption of cloud computing services & AHP & {$[16]$} \\
\hline 4 & Selecting cloud computing deployment model & AHP & {$[40]$} \\
\hline 5 & Ranking of cloud computing services & SAW & {$[28]$} \\
\hline 6 & Public cloud service selection & AHP & {$[41]$} \\
\hline 7 & SaaS vendor selection & ANP & {$[42]$} \\
\hline 8 & Selection of IaaS cloud service & TOPSIS & {$[43]$} \\
\hline 9 & Selection of public cloud service & & {$[29]$} \\
\hline
\end{tabular}


Recent technological developments in cloud computing and its adoption by organizations presents a new set of problems to managers. One of the major problems is the selection of the right MCDM method. Several examples are found in literature where MCDM approach are applied to the decision-making process of cloud computing technology adoption by top managers. Table I provide examples of such problems and applied MCDM methods.

\section{PRoposed Method}

The origin of the proposed method is based on the MultiCriteria Decision-Making (MCDM). The novelty of this method is the use of MCDM in a group decision-making setting where alternatives are ranked with the least amount of variability relative to the mean. Theoretically, the best alternative is the one with the high aggregate mean and low variation values among decision makers. The ratio of deviation to the mean is the coefficient of variation. The proposed method involves the following steps:

Step 1: List the alternatives (A1, A2 A3, Am) where $\mathrm{j} \in \mathrm{m}$ and $\mathrm{m}$ is the number of alternatives

Step 2: Identify the selection criteria $(\mathrm{C} 1, \mathrm{C} 2, \mathrm{C} 3, \mathrm{Cn})$ where $i \in n$ and $n$ is the number of criteria

Step 3: Invite participating decision makers (D1, D2, D3, $\mathrm{Dd})$ where $\mathrm{k} \in \mathrm{d}$ and $\mathrm{d}$ is the number of decision makers

Step 4: Assign importance score $\left(s_{i}^{k}\right)$ of $\mathrm{i}^{\text {th }}$ criterion given by $\mathrm{k}^{\text {th }}$ decision maker. The importance score $\left(s_{i}^{k}\right)$ is assigned using a Likert-type scale ranging from 1 to 7 , where:

$1=$ not at all important

$2=$ not important

3= Somewhat not important

$4=$ neutral

$5=$ somewhat important

$6=$ important

$7=$ very important

The importance score matrix is shown in Table II.

TABLE II. IMPORTANCE SCORE OF ATTRIBUTES $\left(s_{i}^{k}\right)$

\begin{tabular}{|c|c|c|c|c|c|}
\hline Criteria (i) & 1 & 2 & . & & $\mathrm{d}$ \\
\hline 1 & $s_{1}^{1}$ & $s_{1}^{2}$ & . & & $s_{1}^{d}$ \\
\hline 2 & $s_{2}^{1}$ & $s_{2}^{2}$ & . & & $s_{2}^{d}$ \\
\hline . & . & . & . & & . \\
\hline . & . & . & . & & . \\
\hline . & . & . & . & & . \\
\hline $\mathrm{n}$ & $s_{n}^{1}$ & $s_{n}^{2}$ & . & & $s_{n}^{d}$ \\
\hline
\end{tabular}

TABLE III. RELATIVE IMPORTANCE OF ATTRIBUTES $\left(w_{i}^{k}\right)$

\begin{tabular}{|l|l|l|l|l|l|l|}
\hline D. Maker (k) & & & & & & \\
Criteria (i) & 1 & 2 &. &. &. & $\mathrm{~d}$ \\
\hline 1 & $w_{1}^{1}$ & $w_{1}^{2}$ &. &. &. & $w_{1}^{d}$ \\
\hline 2 & $w_{2}^{1}$ & $w_{2}^{2}$ &. &. &. & $w_{2}^{d}$ \\
\hline. &. &. &. &. &. &. \\
\hline. &. &. &. &. &. &. \\
\hline. &. &. &. &. &. &. \\
\hline $\mathrm{N}$ & $w_{n}^{1}$ & $w_{n}^{2}$ &. &. &. & $w_{n}^{d}$ \\
\hline
\end{tabular}

Step 5: Calculate the relative importance $\left(w_{i}^{k}\right)$ of $i^{\text {th }}$ criterion given by $k^{\text {th }}$ decision maker, where:

$$
w_{i}^{k}=s_{i}^{k} /\left(\sum_{i=1}^{n} s_{i}^{k}\right) \text { for } k=1,2, \ldots d
$$

The relative importance score matrix is shown in Table III.

Step 6: Assign importance score $\left(v_{i j}^{k}\right)$ of $i^{\text {th }}$ criterion with respect to the $j^{\text {th }}$ alternative given by the $k^{\text {th }}$ decision maker. The importance score $\left(v_{i j}^{k}\right)$ is assigned using a Likert-type scale ranging from 1 to 7 , where:

$1=$ not at all important

$2=$ not important

$3=$ somewhat not important

$4=$ neutral

$5=$ somewhat important

$6=$ important

$7=$ very important

The importance score matrix is shown in Table IV.

Step 7: Calculate the decision values $\left(u_{i j}^{k}\right)$ of $i^{\text {th }}$ criterion with respect to $j^{\text {th }}$ alternative given by the $k^{\text {th }}$ decision maker, where:

$$
u_{i j}^{k}=w_{i}^{k *} v_{i j}^{k} \text { for } k=1,2, \ldots, d \text { and }\left\{\begin{array}{l}
i=1,2, \ldots n \\
j=1,2, \ldots m
\end{array}\right.
$$

Step 8: Aggregate all decision values $\left(z_{j}^{k}\right)$ of $j^{\text {th }}$ alternative by $k^{\text {th }}$ decision maker, where:

$$
z_{j}^{k}=\sum_{i=1}^{n} u_{i j}^{k} \text { for } k=1,2, \ldots, d \text { and } j=1,2, \ldots, m
$$

Step 9: Calculate the average decision value $\left(\bar{z}_{j}\right)$ of $j^{\text {th }}$ alternative by all decision makers, where:

$$
\bar{z}_{j}=\left(\sum_{k=1}^{d} z_{j}^{k}\right) / d \quad \text { for } j=1,2, \ldots, m
$$

Step 10: Calculate the standard deviation $\left(\sigma_{z_{j}}\right)$ of aggregate decision values of $j^{\text {th }}$ alternative, where:

$$
\sigma_{z_{j}}=\sqrt{\frac{\sum_{k=1}^{d}\left(z_{j}^{k}-\bar{z}_{j}\right)^{2}}{d-1}} \quad \text { for } j=1,2, \ldots, m
$$


Step 11: Calculate the coefficient of variation $\left(c v_{z_{j}}\right)$ of aggregate decision value of $j^{\text {th }}$ alternative, where:

$c v_{z_{j}}=\frac{\sigma_{z_{j}}}{\bar{z}_{j}} \quad$ for $j=1,2, \ldots, m$

The decision value $\left(u_{i j}^{k}\right)$, aggregate decision values $\left(z_{j}^{k}\right)$, average aggregate decision value $\left(\bar{z}_{j}\right)$, and standard deviation $\left(\sigma_{z_{j}}\right)$ and coefficient of variation $\left(c v_{z_{j}}\right)$ of aggregate decision values are presented in Table $\mathrm{V}$.

Step 12: Rank all alternatives and select the best alternative. The best alternative is the one which has the highest mean and lowest standard deviation. That is, the lowest coefficient of variation.

TABLE IV. Importance SCore of Attributes with Respect to Alternatives $\left(v_{i j}^{k}\right)$

\begin{tabular}{|c|c|c|c|c|c|c|c|c|c|c|c|c|c|c|}
\hline \multirow{2}{*}{\begin{tabular}{|r} 
Alternative (j) \\
D. Maker (k)
\end{tabular}} & \multicolumn{3}{|l|}{1} & \multicolumn{4}{|l|}{2} & \multirow[b]{2}{*}{1} & \multirow[b]{2}{*}{2} & & & \multicolumn{3}{|l|}{$\mathrm{m}$} \\
\hline & 1 & 2 & $\mathrm{~d}$ & 1 & 2 & & $\mathrm{~d}$ & & & & $\mathrm{~d}$ & 1 & 2 & $\mathrm{~d}$ \\
\hline 1 & $\mathrm{v}_{11}^{1}$ & $\mathrm{v}_{11}^{2}$ & $\mathrm{v}_{11}^{\mathrm{d}}$ & $\mathrm{v}_{12}^{1}$ & $\mathrm{v}_{12}^{2}$ & & $\mathrm{v}_{12}^{d}$ & & . & & . & $\mathrm{v}_{1 \mathrm{~m}}^{1}$ & $\mathrm{v}_{1 \mathrm{~m}}^{2}$ & $\mathrm{v}_{1 \mathrm{~m}}^{\mathrm{d}}$ \\
\hline 2 & $\mathrm{v}_{21}^{1}$ & $\mathrm{v}_{21}^{2}$ & $\mathrm{v}_{21}^{\mathrm{d}}$ & $\mathrm{v}_{22}^{1}$ & $\mathrm{v}_{22}^{2}$ & . & $\mathrm{v}_{22}^{\mathrm{d}}$ & . & . & . & . & $v_{2 m}^{1}$ & $\mathrm{v}_{2 \mathrm{~m}}^{2}$ & $\mathrm{v}_{2 \mathrm{~m}}^{\mathrm{d}}$ \\
\hline . & . & . & . & . & . & . & . & . & . & . & . & . & . & . \\
\hline & & & . & 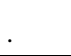 & . & & & & . & & & & & . \\
\hline & & & . & . & . & & & & . & & . & r. & . & . \\
\hline $\mathrm{N}$ & $v_{n 1}^{1}$ & $v_{n 1}^{2}$ & $\mathrm{v}_{\mathrm{n} 1}^{\mathrm{d}}$ & $\mathrm{v}_{\mathrm{n} 2}^{1}$ & $v_{n 2}^{2}$ & & $v_{n 2}^{\mathrm{d}}$ & & . & & & $v_{n m}^{1}$ & $\mathrm{v}_{\mathrm{nm}}^{2}$ & $\mathrm{v}_{\mathrm{nm}}^{\mathrm{d}}$ \\
\hline
\end{tabular}

TABLE V. Decision Value Statistics

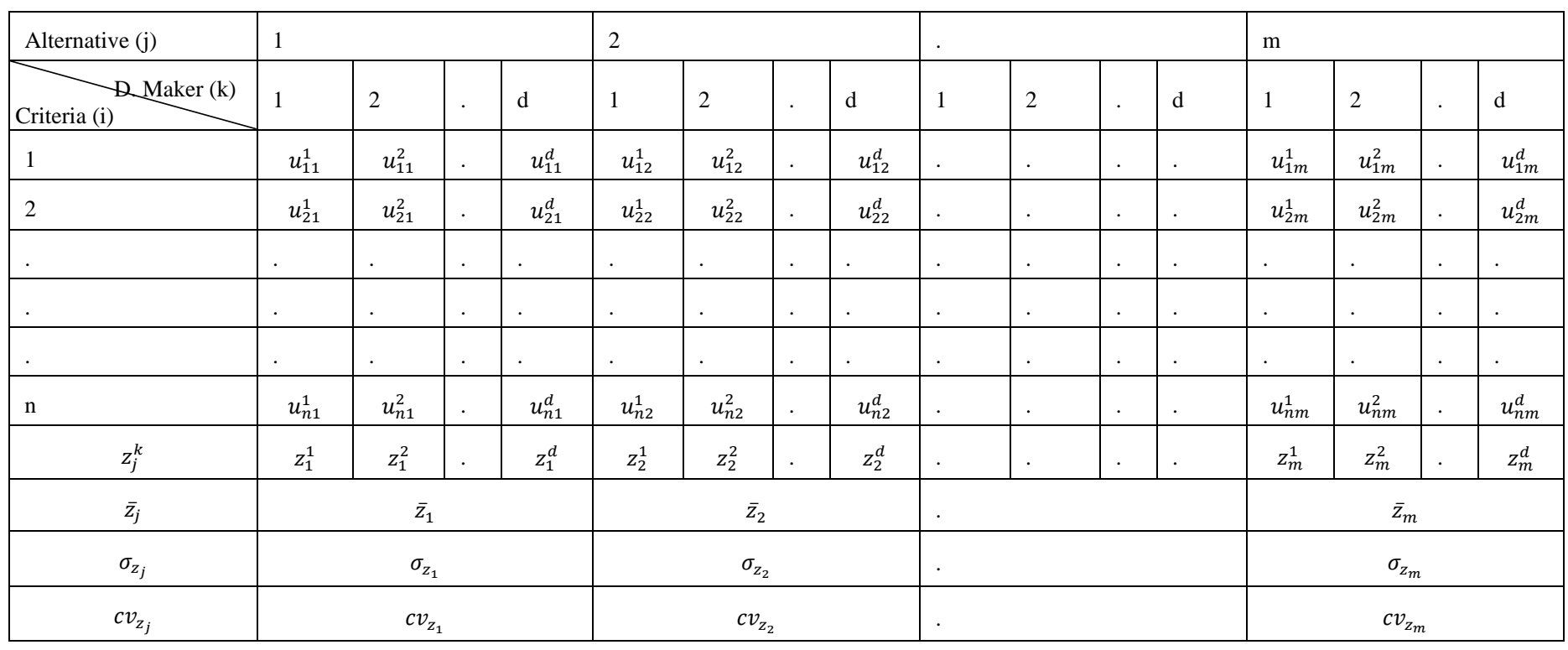

V. AN EXAMPLE

In this section, we present an example to illustrate the process and application of the proposed approach. The example is about a firm wants to identify which cloud service model is suitable for its business requirements and technical environment. There are three options/alternatives (A1, A2 and A3) for service cloud models. There are five decision makers (D1, D2, D3, D4 and D5) who will collaborate to make the suitable decision for the firm. The decision makers will evaluate the alternatives according to seven criteria $(\mathrm{C} 1, \mathrm{C} 2$, $\mathrm{C} 3, \mathrm{C} 4, \mathrm{C} 5, \mathrm{C} 6$ and C7). The decision goal, alternatives, evaluation criteria and decision makers are listed in Table VI.
The criteria are assessed in linguistic terms, using Likerttype scale, as follows:

$1=$ not at all important

$2=$ not important

$3=$ Somewhat not important

$4=$ neutral

$5=$ somewhat important

$6=$ important

$7=$ very important 
TABLE VI. GOAL, CRITERIA AND ALTERNATIVES

\begin{tabular}{|l|l|}
\hline \multirow{2}{*}{ Decision goal } & $\begin{array}{l}\text { Select the cloud computing service model that will be } \\
\text { the most suitable for the firm }\end{array}$ \\
\hline \multirow{4}{*}{ Alternatives } & $\mathrm{A}_{1}:$ Software as a Service (SaaS) \\
& $\mathrm{A}_{2}:$ Platform as a Service (PaS) \\
& $\mathrm{A}_{3}:$ Infrastructure as a Service (IaaS) \\
\hline \multirow{5}{*}{ Criteria } & $\mathrm{C}_{1}:$ Cost of cloud service \\
& $\mathrm{C}_{2}:$ Service adaptability \\
& $\mathrm{C}_{3}:$ IT skills availability \\
& $\mathrm{C}_{4}:$ Urgency of needed cloud service \\
& $\mathrm{C}_{5}:$ Data security \\
& $\mathrm{C}_{6}:$ Dara privacy \\
& $\mathrm{C}_{7}:$ Performance \\
\hline \multirow{5}{*}{ Decision makers } & $\mathrm{D}_{1}:$ Chief executive officer (CEO) \\
& $\mathrm{D}_{2}:$ Chief information officer (CIO) \\
& $\mathrm{D}_{3}:$ Chief technology officer (CTO) \\
& $\mathrm{D}_{4}:$ Chief technology officer (CTO) \\
& $\mathrm{D}_{5}:$ Consultant \\
\hline
\end{tabular}

TABLE VII. IMPORTANCE SCORE OF ATtRIBUtes $\left(s_{i}^{k}\right)$

\begin{tabular}{|c|l|l|l|l|l|}
\hline $\begin{array}{l}\text { Decision Maker (k) } \\
\text { Attribute (i) }\end{array}$ & $\mathrm{D}_{1}$ & $\mathrm{D}_{2}$ & $\mathrm{D}_{3}$ & $\mathrm{D}_{4}$ & $\mathrm{D}_{5}$ \\
\hline $\mathrm{C}_{1}$ & 7 & 7 & 7 & 6 & 7 \\
\hline $\mathrm{C}_{2}$ & 6 & 6 & 7 & 5 & 5 \\
\hline $\mathrm{C}_{3}$ & 4 & 4 & 6 & 3 & 6 \\
\hline $\mathrm{C}_{4}$ & 6 & 6 & 6 & 6 & 6 \\
\hline $\mathrm{C}_{5}$ & 5 & 6 & 4 & 4 & 4 \\
\hline $\mathrm{C}_{6}$ & 7 & 7 & 5 & 6 & 4 \\
\hline $\mathrm{C}_{7}$ & 7 & 6 & 6 & 7 & 7 \\
\hline$\left(\sum_{i=1}^{n} s_{i}^{k}\right)$ & 42 & 29 & 41 & 24 & 39 \\
\hline
\end{tabular}

The decision makers uses the linguistic terms above to rate the general importance of the selection criteria $\left(s_{i}^{k}\right)$, as shown in Table VII.

The relative importance of criteria $\left(w_{i}^{k}\right)$ is calculated using (1), as shown in Table VIII.

TABLE VIII. RELATIVE IMPORTANCE OF ATtRIBUTES $\left(w_{i}^{k}\right)$

\begin{tabular}{|l|l|l|l|l|l|}
\hline \multicolumn{1}{|c|}{ D.M (k) } & $\mathrm{D}_{1}$ & $\mathrm{D}_{2}$ & $\mathrm{D}_{3}$ & $\mathrm{D}_{4}$ & $\mathrm{D}_{5}$ \\
\hline $\mathrm{C}_{1}$ & 0.304 & 0.304 & 0.269 & 0.300 & 0.292 \\
\hline $\mathrm{C}_{2}$ & 0.261 & 0.261 & 0.269 & 0.250 & 0.208 \\
\hline $\mathrm{C}_{3}$ & 0.174 & 0.174 & 0.231 & 0.150 & 0.250 \\
\hline $\mathrm{C}_{4}$ & 0.261 & 0.261 & 0.231 & 0.300 & 0.250 \\
\hline $\mathrm{C}_{5}$ & 0.119 & 0.207 & 0.098 & 0.167 & 0.103 \\
\hline $\mathrm{C}_{6}$ & 0.167 & 0.241 & 0.122 & 0.250 & 0.103 \\
\hline $\mathrm{C}_{7}$ & 0.167 & 0.207 & 0.146 & 0.292 & 0.179 \\
\hline
\end{tabular}

The decision makers rate the importance of criteria with respect to alternatives $\left(v_{i j}^{k}\right)$ using the linguistic terms mentioned above, to rate the importance of the selection criteria, as shown in Table IX.

Using (2), (3), (4), (5) and (6), we compute the decision values $\left(u_{i j}^{k}\right)$, aggregate decision values $\left(z_{j}^{k}\right)$, average aggregate decision value $\left(\bar{z}_{j}\right)$, and standard deviation $\left(\sigma_{z_{j}}\right)$ and coefficient of variation $\left(c v_{z_{j}}\right)$ of aggregate decision values, as shown in Table X.

TABLE IX. ImPortance SCORE of Attributes with ResPeCt to Alternatives $\left(v_{i j}^{k}\right)$

\begin{tabular}{|c|c|c|c|c|c|c|c|c|c|c|c|c|c|c|c|}
\hline \multirow{2}{*}{\begin{tabular}{|l} 
Alternative (j) \\
Criterion \\
(i)
\end{tabular}} & \multicolumn{5}{|c|}{$\mathrm{A}_{1}=\mathrm{SaaS}$} & \multicolumn{5}{|c|}{$\mathrm{A}_{2}=\mathrm{PaaS}$} & \multicolumn{5}{|c|}{$\mathrm{A}_{3}=\mathrm{IaaS}$} \\
\hline & 1 & 2 & 3 & 4 & 5 & 1 & 2 & 3 & 4 & 5 & 1 & 2 & 3 & 4 & 5 \\
\hline $\mathrm{C}_{1}$ & 7 & 5 & 3 & 7 & 7 & 1 & 5 & 5 & 6 & 5 & 7 & 6 & 6 & 5 & 6 \\
\hline $\mathrm{C}_{2}$ & 7 & 6 & 2 & 5 & 5 & 3 & 7 & 5 & 6 & 6 & 7 & 6 & 4 & 7 & 6 \\
\hline $\mathrm{C}_{3}$ & 5 & 4 & 2 & 4 & 7 & 2 & 6 & 7 & 5 & 7 & 5 & 7 & 6 & 7 & 7 \\
\hline $\mathrm{C}_{4}$ & 5 & 6 & 7 & 7 & 7 & 3 & 5 & 6 & 4 & 6 & 3 & 6 & 5 & 3 & 5 \\
\hline $\mathrm{C}_{5}$ & 4 & 5 & 6 & 6 & 6 & 7 & 6 & 5 & 5 & 6 & 7 & 7 & 6 & 5 & 6 \\
\hline $\mathrm{C}_{6}$ & 6 & 5 & 5 & 5 & 5 & 7 & 6 & 6 & 5 & 5 & 6 & 6 & 7 & 7 & 5 \\
\hline $\mathrm{C}_{7}$ & 7 & 6 & 6 & 6 & 4 & 6 & 7 & 6 & 7 & 5 & 5 & 6 & 6 & 7 & 7 \\
\hline
\end{tabular}


TABLE X. Decision Value Statistics

\begin{tabular}{|c|c|c|c|c|c|c|c|c|c|c|c|c|c|c|c|}
\hline \multirow{2}{*}{$\underbrace{\text { Alternative (j) }}_{\text {Attribute (i) }}$} & \multicolumn{5}{|c|}{$\mathrm{A}_{1}=\mathrm{SaaS}$} & \multicolumn{5}{|c|}{$\mathrm{A}_{2}=\mathrm{PaaS}$} & \multicolumn{5}{|c|}{$\mathrm{A}_{3}=\mathrm{IaaS}$} \\
\hline & 1 & 2 & 3 & 4 & 5 & 1 & 2 & 3 & 4 & 5 & 1 & 2 & 3 & 4 & 5 \\
\hline $\mathrm{C}_{1}$ & 2.130 & 1.522 & 0.808 & 2.100 & 2.042 & 0.304 & 1.522 & 1.346 & 1.800 & 1.458 & 2.130 & 1.826 & 1.615 & 1.500 & 1.750 \\
\hline $\mathrm{C}_{2}$ & 1.826 & 1.565 & 0.538 & 1.250 & 1.042 & 0.783 & 1.826 & 1.346 & 1.500 & 1.250 & 1.826 & 1.565 & 1.077 & 1.750 & 1.250 \\
\hline $\mathrm{C}_{3}$ & 0.870 & 0.696 & 0.462 & 0.600 & 1.750 & 0.348 & 1.043 & 1.615 & 0.750 & 1.750 & 0.870 & 1.217 & 1.385 & 1.050 & 1.750 \\
\hline $\mathrm{C}_{4}$ & 1.304 & 1.565 & 1.615 & 2.100 & 1.750 & 0.783 & 1.304 & 1.385 & 1.200 & 1.500 & 0.783 & 1.565 & 1.154 & 0.900 & 1.250 \\
\hline $\mathrm{C}_{5}$ & 0.476 & 1.034 & 0.585 & 1.000 & 0.615 & 0.833 & 1.241 & 0.488 & 0.833 & 0.615 & 0.833 & 1.448 & 0.585 & 0.833 & 0.615 \\
\hline $\mathrm{C}_{6}$ & 1.000 & 1.207 & 0.610 & 1.250 & 0.513 & 1.167 & 1.448 & 0.732 & 1.250 & 0.513 & 1.000 & 1.448 & 0.854 & 1.750 & 0.513 \\
\hline $\mathrm{C}_{7}$ & 1.167 & 1.241 & 0.878 & 1.750 & 0.718 & 1.000 & 1.448 & 0.878 & 2.042 & 0.897 & 0.833 & 1.241 & 0.878 & 2.042 & 1.256 \\
\hline$z_{j}^{k}$ & 6.000 & 7.724 & 4.244 & 9.042 & 5.897 & 5.000 & 8.655 & 5.707 & 8.500 & 5.692 & 5.738 & 9.034 & 5.634 & 8.958 & 6.077 \\
\hline$\overline{z_{j}}$ & 6.581 & & & & & 6.711 & & & & & 7.088 & & & & \\
\hline$\sigma_{z_{j}}$ & 1.846 & & & & & 1.729 & & & & & 1.750 & & & & \\
\hline$c v_{z_{j}}$ & 0.280 & & & & & 0.258 & & & & & 0.247 & & & & \\
\hline Ranking & 3 & & & & & 2 & & & & & 1 & & & & \\
\hline
\end{tabular}

Based on the least ratio of variability $c v_{z_{j}}$ among the decision makers, the alternatives are ranked as IaaS, PaaS and SaaS. Therefore, IaaS is the most preferred cloud service model for the firm, followed by PaaS and SaaS.

\section{CONCLUSION AND FUTURE WORK}

In this paper, we have identified a set of important factors for selecting cloud computing service models. These factors are available budget, adaptability to changing user requirements, available IT skills, urgency of needed service, data security, data privacy and reliability of service. We also proposed a novel multi-criteria approach that takes into consideration the aggregate mean of decision values and the deviations values among the decision makers. Despite the novelty of this approach, it can be improved by adding more selection criteria, like interoperability, performance, scalability, compatibility, complexity and vendor credibility and support.

\section{ACKNOWLEDGMENT}

This project was funded by the National Plan for Science, Technology, and Innovation (MAARIFAH) - King Abdulaziz City for Science \& Technology through the Science \& Technology Unit at King Fahd University of Petroleum \& Minerals - Kingdom of Saudi Arabia, award number (14INF83-04).

\section{REFERENCES}

[1] A. Bartels, J.R. Rymer, J. Staten, K. Kark, J. Clark, and D. Whittaker, "The Public Cloud Market Is Now in Hypergrowth: Sizing The Public Cloud Market, 2014 To 2020", Forresters, available at https://www.forrester.com/report/The+Public+Cloud+Market+Is+Now+ In+Hypergrowth/-/E-RES113365 (accessed 10 January 2017).

[2] F. Etro. "The Economics of Cloud Computing", The IUP Journal of Managerial Economics, Vol. 9, No. 2, 2012, pp. 7-22.
[3] CEBR. Economic impact of cloud computing. Centre for European Business Research, 2011.

[4] A. Azadegan and J. Teich, "Effective benchmarking of innovation adoptions: A theoretical framework for e-procurement technologies", Benchmarking: An International Journal, Vol. 17, No. 4, 2010, pp. 472490.

[5] I.M. Al-Jabri and M.H. Alabdulhadi, "Factors affecting cloud computing adoption: perspectives of IT professionals", International Journal of Business Information Systems, Vol. 23, No. 4, 2016, pp.389-405.

[6] I.M. Khalil, A. Khreishah, and M. Azeem, "Cloud Computing Security: A Survey", Computers, Vol. 3, No. 1, 2014, pp. 1-35.

[7] K.M. Khan, A. Erradi, S. Alhazbi, and J. Han, "Addressing security compatibility for multi-tenant cloud services" International Journal of Computer Applications in Technology, Vol. 47, No. 4, 2013, pp. 370378.

[8] T. Radwan, M.A. Azer, and N. Abdelbaki, "Cloud computing security: challenges and future trends", International Journal of Computer Applications in Technology, Vol. 55, No. 2, 2017, pp.158-172.

[9] D. Servos, S. Mohammed, J. Fiaidhi, and T. Kim, "Extensions to ciphertext-policy attribute-based encryption to support distributed environments", International Journal of Computer Applications in Technology, Vol. 47, No.2/3, 2013, pp. 215-226.

[10] S. Singha, Y. Jeong, and J.H. Park, "A survey on cloud computing security: Issues, threats, and solutions", Journal of Network and Computer Applications, Vol. 75, 2016, pp. 200-222.

[11] A. Tashkandi and I. Al-Jabri, "Cloud Computing Adoption by Higher Education Institutions in Saudi Arabia: An Exploratory Study", Cluster Computing, Vol. 18, No. 4, 2015, pp. 1527-1537.

[12] M.F. Mushtaq, U. Akram, I. Khan, S.N. Khan, A. Shahzad, and A. Ullah, "Cloud Computing Environment and Security Challenges: A Review", International Journal of Advanced Computer Science and Application, Vol. 8, No. 10, 2017, pp. 183-195.

[13] M. Kazim and S.Y. Zhu, "A survey on top security threats in cloud computing", International Journal of Advanced Computer Science and Application, Vol. 6, No 3, 2015, pp.109-113.

[14] R. El-Gazzar, E. Hustad, and D.H. Olsen, "Understanding cloud computing adoption issues: A Delphi study approach", The Journal of Systems and Software, Vol. 118, 2016, pp. 64-84. 
[15] A. Basahel, M. Yamin, and A. Drijan, "Barriers to Cloud Computing Adoption for SMEs in Saudi Arabia", BVICAM's International Journal of Information Technology, Vol. 8, No. 2, 2016, pp. 1044-1048.

[16] S. Khan, M.S.A. Khan, and C.S. Kumar, "Multi-criteria Decision in the Adoption of Cloud Computing Services for SME's based on BOCR Analysis", Asian Journal of Management Research, Vol. 5, No. 4, 2015, pp. 606-619.

[17] F.M. Aymerich, G. Fenu, and S. Surcis, "An Approach to a Cloud Computing Network", 1st International Conference on the Applications of Digital Information and Web Technologies, Ostrava, Czech Republic, August 4-6, 2008, pp. 120-125.

[18] R. Buyya, C.S. Yeoa, and S. Venugopala, J. Broberg and J. Brandic, "Cloud computing and emerging IT platforms: Vision, hype, and reality for delivering computing as the 5th utility", Future Generation Computer Systems, Vol. 25, 2009, No. 6, pp. 599-616.

[19] Jaeger, P.T., J. Lin, and J.M. Grimes. Cloud computing and information policy: computing in the policy cloud?. Journal of Information Technology \& Politics, Vol. 6, No. 3, 2008, pp. 269-283.

[20] M.A. Vouk, "Cloud Computing - Issues, research and implementations", Journal of computing and information technology, Vol. 16, No. 4, 2008, pp. 235-246.

[21] S. Biswas, "Cloud Computing vs Utility Computing vs Grid Computing. Cloud Tweaks", available at http://cloudtweaks.com/2011/02/cloudcomputing-vs-utility-computing-vs-grid-computing-sorting-thedifferences/ (accessed 10 January 2017)

[22] N.G. Carr, "IT Doesn't Matter", Harvard Business Review, available at http://hbr.org/2003/05/it-doesnt-matter (accessed 22 March 2017)

[23] M. Armbrust, A. Fox, R. Griffith, A.D. Joseph, R. Katz, A. Konwinski, G. Lee, D. Patterson, A. Rabkin, I. Stoica, and M. Zaharia, "A View of Cloud Computing", Communications of the ACM, Vol. 53, No. 4, 2010, pp. $50-58$.

[24] F. Kramer, "Musings on the cloud - A customer oriented concept formation on cloud computing with respect to SME", European, Mediterranean \& Middle Eastern Conference on Information Systems (EMCIS2012), Munich, Germany, June 7-8, 2012.

[25] P. Mell and T. Grance, The NIST Definition of Cloud Computing. National Institute of Standards and Technology (NIST). US Department of Commerce. Special Publication 800-145. 2011.

[26] Computer Security Alliance, "Security Guidance for Critical areas focus in Cloud Computing v3.0", 2011, available at https://cloudsecurityalliance.org/guidance/csaguide.v3.0.pdf (accessed 22 March 2017).

[27] M.I. Eid, I.M. Al-Jabri, M.S. Sohail, and K.J. Syed "Cloud computing adoption: a mapping of service delivery and deployment models", 15th International Conference on Electronic Business, Hong Kong, December 6-10, 2015, pp. 160-165.

[28] S.K. Garg, S. Versteeg, and R. Buyya, "A framework for ranking of cloud computing services", Future Generations Computer Systems Journal, Vol. 29, No. 4, 2013, pp. 1012-1023.

[29] P. Saripalli and G. Pingali, "MADMAC: Multiple Attribute Decision Methodology for Adoption of Clouds", 4th International Conference on Cloud Computing, Washington, DC, USA, July 4-9, 2011, pp. 316-323. IEEE Xplore, DOI: 10.1109/CLOUD.2011.61

[30] F. De Borja, "Cloud Computing Skills Required for IT Employees. Cloud Times", available at http://cloudtimes.org/2013/02/06/cloud- computing-skills-required-for-it-employees/ (accessed 23 February 2017).

[31] E.O. Yeboah-Boateng and K.A. Essandoh, "Factors Influencing the Adoption of Cloud Computing by Small and Medium Enterprises in Developing Economies", International Journal of Emerging Science and Engineering, Vol. 2, No. 4, 2014, pp. 13-20.

[32] E.O. Güner and E. Sneiders, "Cloud Computing Adoption Factors in Turkish Large Scale Enterprises", PACIS 2014 Proceedings, Chengdu, China, June 24-28, 2014. http://aisel.aisnet.org/pacis2014/353 (accessed 17 April 2017).

[33] L. Sun, H. Dong, F.K. Hussain, O.K. Hussain, and E. Chang, "Cloud service selection: State-of-the-art and future research directions", Journal of Network and Computer Applications, Vol. 45, No. 1, 2014, pp. 134-150.

[34] R.K. Gavade, "Multi-Criteria Decision Making: An overview of different selection problems and methods", International Journal of Computer Science and Information Technologies, Vol. 5, No. 4, 2014, pp. 5643-5646.

[35] G. Conway, and E. Curry, "The IVI Cloud Computing Life Cycle", in: Ivanov, I.I., M. van Sinderen, F. Leymann, T. Shan (Eds) Cloud Computing and Services Science, Communications in Computer and Information Sciences, Vol. 367, Springer, Cham, 2013, pp. 183-199. DOI: 10.1007/978-3-319-04519-1_12

[36] M. Whaiduzzaman, A. Gani, N.B. Anuar, M. Shiraz, M.N. Haque, and I.T. Haque, "Cloud Service Selection Using Multi-criteria Decision Analysis", The Scientific World Journal, Volume 2014, Article ID 459375, pp 1-10.

[37] Z. Rehman, O.K. Hussain, and F.K. Hussain, "IaaS Cloud Selection using MCDM Methods", 9th International Conference on e-Business Engineering, Hangzhou, China, September 9-11, 2012, pp. 246-251. IEEE Xplore, DOI: 10.1109/ICEBE.2012.47

[38] S. Lee and K. Seo, "A Hybrid Multi-Criteria Decision-Making Model for a Cloud Service Selection Problem Using BSC, Fuzzy Delphi Method and Fuzzy AHP", Wireless Personal Communications, Vol. 86, No. 1, 2016, pp. 57-75.

[39] S. Liu, F.S. Chan, and W. Ran, "Decision making for the selection of cloud vendor: An improved approach under group decision-making with integrated weights and objective/subjective attributes", Expert Systems with Applications, Vol. 55, No. 1, 2016, pp 37-47.

[40] N. Ramachandran, P. Sivaprakasam, G. Thangamani, and G. Anand. "Selecting a suitable Cloud Computing technology deployment model for an academic institute: A case study", Campus-Wide Information Systems, Vol. 31, No. 5, 2014, pp. 319-345.

[41] C.P. Muir, "Decision Making Model for the Adoption of Cloud Computing in Jamaican Organizations", 19th Americas Conference on Information Systems, August 15-17, 2013, Chicago, Illinois.

[42] C. Yiming and Z. Yiwei. "SaaS vendor selection basing on Analytical Hierarchy Process", 14th International Joint Conference on Computational Sciences and Optimization, Yunnan, China, April 15-19, 2011 pp. 511-515, IEEE Xplore, DOI: 10.1109/CSO.2011.232.

[43] M. Menzel, M. Schonherr, J. Nimis, and S. Tai, "(MC2)2: A Generic Decision-Making Framework and its Application to Cloud Computing", available online: https://arxiv.org/abs/1112.1851 (accessed on 2 December 2017). 